\title{
BEYOND THE BUMP: RECONCEIVING THE PHILOSOPHY OF PREGNANCY
}

\author{
Hazel T. Biana \\ Leni dIR. Garcia \\ De La Salle University, Philippines
}

\author{
Ninotchka Mumtaj B. Albano \\ Ateneo de Manila University, Philippines
}

For Saoirsha, Sedona, and all daughters and sons born of the bump.

\begin{abstract}
French philosopher Hélène Cixous (1976) stressed the importance of feminine writing. She believes that women should take part in sharing their experiences from their own novel points-of-view. We discuss that while pregnancy is an experience unique to women, it has been misappropriated by patriarchal structures throughout the years. The pregnancy bump, which is more than just evidence of the uterus stretching to accommodate the fetus, is a symbol of a woman's triumphs and struggles all throughout conception, pregnancy, and childbirth. We show that women have already gone beyond the bump and challenged existing patriarchal systems through different means, as Cixous has enjoined women to do. With this, it is asserted that the philosophy of pregnancy be reconceived as well, in order to escape existing boundaries that constrict the discourse to ethical issues of rape, abortion, and medical interventions, making it face issues that surround women's experience of pregnancy, as well as deeper meanings the pregnant body itself represents.
\end{abstract}

\section{INTRODUCTION}

The nature of pregnancy is not a common topic in Philosophy (Tyler 2000, 294). Most philosophical works on pregnancy tend to focus on the ethics of contraception, abortion, in vitro fertilization, and surrogacy. This presupposes that pregnancy is just a matter of moral choice and that there are no other pertinent issues that surround it. Feminist philosophers assert otherwise and believe that there is philosophical importance to pregnancy as specifically a woman's lived experience.

While it is apparent that women are the ones who actually get pregnant, they are often left out of pregnancy theory and praxis. Indeed, as Hélène Cixous claims (1976), women's voices have been repressed and undermined throughout history. While some 
thinkers describe how patriarchal systems have dispossessed pregnancy from women, there must be a constant push in responding to phallocentric and patriarchal traditions. As one of those misappropriated experiences, women should take part in sharing their experiences on pregnancy from their own novel points-of-view.

The pregnancy bump, which is more than just evidence of the uterus stretching to accommodate the fetus, is a symbol of women's triumphs and struggles all throughout conception, pregnancy, and childbirth. Fortunately, there is a way to rewrite pregnancy. We do this by reviving positive images of pregnancy from ancient to contemporary times as counter-discourse to oppressive ones. Through this exercise, we make a case for the philosophy of pregnancy to be reconceived and go beyond the usual parameters that have been assigned to it, thereby encouraging women to regain control of the whole birthing process (Bibby 1996, 111).

\section{THE MISAPPROPRIATION OF PREGNANCY}

Various philosophers who are women (See Beauvoir 2011, Guenther 2013, 89, Mullin 2005, Diprose 1994, Gray 2013, 71-87 and Butterfield 2010, 65-76) have written about pregnancy in an attempt to articulate their unique vantage points. Their main claim revolves around the assertion that patriarchal systems have misappropriated pregnancy. For example, Adrienne Rich (1975) talks of the theft of childbirth as the patriarchal exploitation of the woman's labor processes. Simone de Beauvoir (2011, 612-613), on the other hand, explains that a pregnant woman's body is not her own, as society demands so many things from women after they conceive.

In The birth of sexual difference: A feminist response to Merleau-Ponty (2013), Lisa Guenther $(2013,89)$ contends that during pregnancy, the woman is reduced to becoming a "container" while the child's future is reduced "to a present waiting to be unpacked from its box." Through nature, the child that swells in her womb makes her "a collection of colloids, an incubator, an egg" (Beauvoir 2011, 613). Beauvoir (2011, 613) believes that this makes the woman "a passive instrument of life." While a woman thinks she is victorious in creating life, she is accordingly also "alienated in her body and her social dignity" (Beauvoir 2011, 613-614; 625).

Women are led to believe that when they get pregnant, they have found what they have been searching for all their lives. However, a mother experiences frustration as soon as she gives birth. Her anticipation leads her to imagine and fantasize about her expectations of her child. With little knowledge of how the child would be, she finds out that she is faced with something less spectacular, less of what she imagined her child to be:

In her pregnancy reveries, he was an image, he was infinite, and the mother mentally played out her future motherhood; now he is a tiny, finite individual; he is really there, contingent, fragile, demanding. The joy that he is finally here, quite real, is mingled with the regret that this is all he is. (Beauvoir 2011, 625)

Beauvoir terms pregnancy as the "annihilation of the self" (2011). Due to societal expectations, pregnancy is a drama of extreme polarities (Beauvoir 2011, 612- 
613). It is an enrichment and mutilation, a part of the body as a fetus and a parasite, a possession and being possessed by it at the same time. When a woman is pregnant, her pregnancy encapsulates the future, but it annihilates her as well. It makes the woman as vast as the world but also gives the impression that she is nothing else but a pregnant individual. While the pregnant woman manifests a new existence, she is also a plaything of obscure forces. Moreso, in the eyes of a patriarchal society, which demands that pregnant women should no longer live for themselves and devote their futures towards breeding and nurturing children (Beauvoir 2011, 612-613).

On the other hand, when it comes to childbirth, women's experiences seem to be more devastating than that of industrial workers'. Apparently, there is no psychic or physical bond with the product (or the baby for that matter) or the service (labor) (Bibby 1996, 111). Motherhood (an umbrella term which is, in Rich's case, used to refer to conception, pregnancy, and childbirth), as a cultural role and embodied experience, has been stolen from women by patriarchy. Some instances include treating childbirth as a crisis, the intrusion of drugs in the birthing process, episiotomies, fetal monitoring and intervention, and the rise of performed Caesarean sections. The almost-immediate separation of mother and child after birth constitutes the so-called theft of childbirth (Ehrenreich and English 1978, 29). Consequently, it is the doctor who is seen as the hero of childbirth when he or she delivers the baby (Ehrenreich and English 1978, 29).

\section{TOWARDS REWRITING PREGNANCY}

Fortunately, Beauvoir's and Rich's doomed assertions on the nature of pregnancy may be averted. Despite certain experiences being "stolen from women," Cixous (1976) claims that a shift from male-dominant positions to a female standpoint is possible. Countering phallocentric and patriarchal traditions may be done through the reformulation of language. In The laugh of the Medusa (1976), we see that rewriting and reformulating the structures of language may eventually address restrictions put upon women.

Cixous (1976) uses the myth of Medusa to demonstrate her point. Medusa is seen as a monster, an ugly, angry figure with snakes for her hair. Medusa is projected as a villain who has this treacherous power of turning anyone to stone if one looks directly into her eyes. Accordingly, this negativity is depicted as such by men. In Freud's essay entitled Medusa's head (1963), he $(1963,212)$ identifies the decapitated head of Medusa as a representation of the female genitals - wherein the absence of the penis is deemed as castration. The "sight of Medusa's head makes the spectator stiff with terror, turns him to stone."

The projection of Medusa is an example of a male-dominated image that prompts Cixous's call for women to revise these images by writing their own history. She insists that a "new insurgent" is needed against these kinds of phallocentric structures through feminine writing — which also acts as the "pre-cursory movement of a transformation of social and cultural structures" (Cixous 1976, 879). 
The struggle against these structures also includes a revelation of how the female body is stolen and confiscated from the woman herself (Cixous 1976, 879). Patriarchal systems have always established that the female body is one of shame and that it should always be kept hidden. Women are taught to be conservative and that they should censor their bodies as well as their speech. With the "new insurgence," Cixous insists that women should flaunt their bodies, instead, joining a revolt of laughter rather than fury, reclaiming the beautiful Medusa who has been painted by patriarchy an ugly, angry monster with snakes for hair. Pregnant women and their pregnant bodies are not grotesque, and therefore should not be shamed; they are beautiful and glorious. Pregnancy is an affirmation of this beauty and glory, and women have already started articulating their experience of it.

In Original habitation: Pregnant flesh as absolute hospitality (2013), Frances Gray $(2013,72)$ maintains "that (a) pregnant woman is not just body, but (a) living body, living experience." She $(2013,72)$ echoes Luce Irigaray's "twoness" where individuation is possible in the pregnant body, and Merleau-Ponty's (Guenther 2013, 88108) take on the "flesh," which is an element that is neither just a body nor mind. The woman's body is not necessarily mutilated or destroyed, but it becomes a "living experience." It is a relationship that involves the intersubjectivity of two individuals who mutually benefit from each other. Pregnancy does not become a sacrifice or a process of surrendering one's freedom, but a process of transcending by virtue of a woman's choice to bear offspring. Both mother and child benefit from this othering, this mutual transformation.

This same view is asserted in The vision of the artist/mother: The strange creativity of painting and pregnancy, where Florentien Verhage $(2013,300)$ notes that as a lived experience, pregnancy and birthing are a creative process where women's vision as both a mother and artist takes place. The image of the woman in her pregnant state introduces an experience that transforms her changing body into a "waiting condition."

Women have been generally identified with their body where their flesh is described as a smoldering hatchery that produces and sustains life. By being solely concerned with the unborn child, society forgets the woman as the essential origin and central body in the experience of pregnancy (Verhage 2013, 302). However, as Verhage (2013, 301-302) reveals, a woman's pregnant body must neither be regarded as passive nor merely subjectless. Akin to an artist, a pregnant body is a medium of lived creativity transforming positive and resilient images of both woman and her child. The transformation of a woman's body takes part in the image-making, her image, and her pregnancy as her own. This opposes the societal and patriarchal fixation of equating pregnancy to the unborn child, fetal images, or sonograms. Pregnancy then becomes an artistic process of imaging as images of women's bodies are transformed and celebrated through pregnancy instead of sheer ceremonial concepts of birthing and human production.

In her Days and nights of a new mother: Existentialism in the nursery (2010), Elizabeth Butterfield $(2010,69)$ recalls her experience as a new mother and how she pondered on the existential questions that resulted from it. She chronicles the routine of tending to a crying baby, the endless task of feeding, changing, cooing, and loving her child while realizing that she was in the middle of the process of self-loss. This 
loss of self is felt as genuinely life-changing in a beautiful way. She found meaning in what she was doing, and she was aware of her individual self. There is no definite essence of the "ideal maternal." The "ideal mother" is a social construction, and one that varies historically and culturally" (Butterfield 2010,67). Any expectation that one might have about pregnancy or motherhood is not necessarily an illusion or a mistake, but the social construction of what a mother is, or what her experiences are, differs from mother to mother. The unique experience in childbearing does not necessarily apply to another. One must but "replace it with the more realistic account of the mother as always also a work in progress" (Butterfield 2010, 74).

Furthermore, women must be reframed as "active subjects of their own gestation" (Tyler 2000, 292). Through first-person, subjective narration, and visual representations, the unique temporality of the pregnant existence may be embodied. The pregnant woman should speak of her own experience through her own voice and not how society sees her. In this regard, Iris Marion Young discusses her own pregnancy (Tyler 2000, 296). Rather than losing her subjectivity, Young claims that various changes in one's body during pregnancy make a woman more aware of her own body. This sharp awareness gives the woman more importance (Mullin 2005, 20).

While Beauvoir and Rich insisted on the oppressive nature of pregnancy in the context of the existing patriarchal society, it is shown here that other thinkers believe such a view can be overturned. When more women write about pregnancy through their beautiful experiences, we can "wreck partitions, classes, and rhetorics, regulations and codes" (Cixous 1976, 886). A stronger case is made when these rewritings are coupled with a reframing of visual representations of women.

\section{IMAGES OF PREGNANCY: FROM ANCIENT TO CONTEMPORARY TIMES}

In prehistoric times when the role of the males in procreation was still unknown, the mother was the center of all relationships. The family consisted mainly of the mother and her children because "[i]t was believed that only women held the divine power to give life" (Walker 1983, 680). This accounts for primitive mythologies invoking the name of the Creatress, not the Creator. She was the Great Goddess or the Divine Ancestress, worshipped from as far back as 25,000 BCE until about 500 CE. (Stone 1976, xii) Their childbearing and nurturing capacities made them as valuable as the land they cultivated. These afforded them power that later evolved as matriarchy (Walker, 1983, 680-81). Thus, before pregnancy and childbearing were deemed "the curse of Eve," ancient myths and rituals exhibited how the woman's body was honored as a vessel for the recreation of the world. The pregnant body is identified with the broad sense of fertility, not just in terms of procreation, but the fertility of the land in its floro-faunistic sense. The pregnant body was, in a sense, revered, as was the goddess.

Paleolithic images of pregnancy represented through fertility goddesses exhibit her swelling breasts and bloated belly as a positive signifier of veneration, hope, health, and prosperity (Nešic 1998, 747-748). Consequently, the absence or death of a woman 
and her child is viewed as a catastrophic circumstance that was not only mourned but memorialized.

During the Hellenic and Hellenistic periods, small statues of women were popular images. Among them are depictions of pregnant women. In ancient Greece, women were valued as breeders of healthy children, preferably sons. Funerary stelae and vases commemorate women who died in childbirth, such as the Attic lekythos with the scene of a midwife holding the limp body of a dead pregnant mother while the husband looks on in grief. (Nešic 1998, 748-749)

"Venus figures" from the Paleolithic period in different parts of the world illustrates the centrality of pregnancy and childbirth in ancient myths. These figurines have been described as "carved in bone, stone, or mammoth ivory, are nude, and simply standing. many are extremely obese... [emphasize] the great loins, the pubic triangle, and the nourishing breasts," some have "extravagant breasts reaching even to the groins" while some are "prominently pregnant" (Campbell 1976, 313, 326). The Austrian Venus of Willendorf (25,000-15,000 b.c.), and the Romanian Fertility Goddess of Cernavoda (5,000 b.c.) are early instances of "Venus figures" while the Neolithic Fertility Goddess (6000 b.c.) of Çatal Hüyük in Anatolia, Turkey appears to be a remodeled version of these carved images. The first two are described to be quite small, standing at only 4.75 and 6.25 inches while the latter "sits on a birthing chair. Enthroned, she becomes a sign of fertility and a site of power. In early matriarchal societies, the queen would sit on the lap of the enthroned mother-goddess to symbolize her union with the goddess's power"'(Nešic 1998, 747). These images represent "the same mother-goddess who was to become so conspicuous in the later agricultural civilizations of the Near East and has been everywhere celebrated as the Magna Mater and Mother Earth" (Campbell 1976, 314).

Even the sacredness of ancient round or oval symbols derives from the pregnant belly, which gives birth to the Universe. "...Everything and everywhere is circular in most pictographic or alphabetic systems. Birth is roundness: the pregnant belly, the full breast... Vessels are round. The house is round, containing all stages of life..." (Walker 1988, 2). The woman's body as a procreative vessel identifies her with the agricultural cycle. The land, just like the woman, allows the cyclic process of sowing and reaping, encompassing birth, death, and rebirth. Her own menstrual cycle is like the waxing and waning of the moon. This is why most deities in charge of fertility are female. Everyone comes into the world through the mother who alone has a womb. Even when the male god is identified with fertility, as in the case of the Egyptian myth of Osiris, it is through the goddess that his position as such is secured (Ions 1968, 58). To trace the demise of the goddesses who were central in ancient myths of Sumer, the goddesses took care of domains that are connected to Earth, not the Sky, and their connection to it is through their bodies (Frymer-Kensky 1993, 46 - 47). In fact, the "wanton goddess" Innana (or Ishtar), the goddess who cannot be domesticated, feels marginalized and lost. On the one hand, her not being so "womanly" keeps her out of the usual roles given to female deities. Since she does not get pregnant, give birth, or rear children, she has a "role in war, and of her ability to transcend and reverse 
boundaries...but her great power and authority are ill-defined. Having a great variety of powers and roles, she nevertheless does not fit any of the niches that society has provided for its women" (emphasis supplied) (Frymer-Kensky 1993, 27).

Innana's lack of interest in becoming pregnant and giving birth makes her some sort of a misfit in the pantheon. However, Innana stands as the goddess of sexuality, the necessary ingredient that leads to reproduction and fertility (Frymer-Kensky 1993, 58). The prominence of the woman's body and its associations with sex, reproduction, and fertility in ancient myths and rituals show how important it is in the maintenance of the cosmos, which in turn takes care of day to day life. Because of this, Earth has always been seen as "mother" and is the archetypal provider of nourishment, going through birth, growth, death, and rebirth, in its cyclic process of renewal. Why are there no heroes who are women? Campbell (Keen and Fox 1989, xx) replies that "[w]omen are set inexorably on the heroic path through childbirth and the challenge of maternity." Giving birth is a heroic deed in that it is the giving over of oneself to the life of another.

Early Christian art or paleo-Christian art resumed the idolization of pregnant women. However, unlike her Paleolithic and Neolithic counterparts, "[t]he Virgin's pregnancy connotes not fertility but self-sacrifice - the giving of oneself (and one's most prized possession, virginity) for the greater good. Thus, statues of the pregnant Virgin become devotional images and paradigms of the ideal woman" (Nešic 1998, 748). The image of the pregnant Virgin predominantly occupies the image of pregnancy in this era. An instance of which is Madonna del Parto (1460), a $14^{\text {th }}$-century fresco by Piero della Francesca where a very pregnant Virgin Mary appears under a canopy, surrounded by two angels. Images of the pregnant Virgin as carvings such as "[a] fourteenth-century apse fresco in San Abondio Basilica in Como, Italy...[a] painting by the Master of the Cologne School (circa 1410); a fresco in St. Georg zu Rhäzüns in Graubümden, Switzerland (1375); an initial in a Cistercian gradual (circa 1340); and a miniature from the Pontificale di Würzburg in Germany (circa 1507)" (Nešic 1998, 749).

Issuing from this early Christian exaltation, figures of pregnancy evolved and delegated the image to depictions of sickness such as The Anaemic Lady (1667) by Samuel van Hoogstraand where a poor woman is equated to a suspected pregnancy and images associated with hunger or appetite in Honoré Daumier's lithograph, Une envie de femme grosse (1840). In the latter image, "a pregnant bourgeois wife tries to take a bite out of the butcher's arm while he carries a tray full of meat. Meanwhile, her husband grabs her arm and pulls her back, exhibiting his annoyance and exercising the manly duty of controlling his wife" (Nešic 1998, 749). The burden of pregnancy has likewise tinted works that depict shame, poverty, and grief. Shame in pregnancy is often identified with images of women in the act of concealing their swollen bellies. This act is a response to either an embarrassment towards their enlarged physiques or society's unease in having to associate pregnancy with a sexually active woman or the sin of fornication. "The shame of lost virginity and illegitimacy is given a much more straightforward treatment in Godfried Schalcken's La consultation indiscrète (1680 1685) and its pendant La remonstrance inutile (1685-1690)" (Nešic 1998, 750). In 
both works, the father's disappointment towards the frail condition of his daughter is agitated by the affirmation of her pregnancy or miscarriage. Both paintings infer that pregnancy incites various emotions, opinions, and behaviors toward the human condition (Nešic 1998, 752).

Artists may also opt to "reflect the Victorian preference for hiding the look of pregnancy from public view" (Nešic 1998, 750) such as Raphael's La Gravida (15051507), Thomas Couture's La Lecture (1860), Berthe Morisot's works such as Madame Morisot et sa fille Madame Pontillon (La Lecture), (1869-1870), Intérieur 1871, (1871), Portrait de Madame Pontillon (1871), and Madame Pontillon et sa fille Jeanne sur un canapé (1871) (Nešic 1998, 752).

Unlike shame, however, no other situation seems to strain one's experience other than poverty. Alphonse Levy's lithograph Ça, c'est pour les riches (1880), illustrates "a poor pregnant woman standing outside a bakery shop with a baby in her arms and a toddler at her side, eyeing the cakes and chocolates in the window." Pablo Picasso's The soup (1903), Käthe Kollwitz's etching Woman with Folded Hands (1898), At the Doctor's (1908-1909), and her The Widow I (1922-1923) all depict the biological, economic, and psychological exhaustion of "bringing a new life into a poor family" (Nešic 1998, 750). Akin to Picasso and Kallowitz, themes of poverty influence images of sorrow, such as Vincent van Gogh's Sorrow (1882) and Pablo Picasso's The Embrace (1903). These works portray the overwhelming agonies that women face in their pregnant lives, accompanied by childbirth.

Arising from the negative connotations, representations of pregnancy have progressed to rewrite the abundance and fertility of women during the prenatal stage via positive images of hope and happiness. Gustav Klimt's Hope I (1903) and Hope II (1907-08) deliver just that - a glimmer of hope in the otherwise difficult and challenging circumstance of a pregnant woman. Klimt's Hope $I$ finds a pregnant nude woman gazing into the spectator; with tiny flowers in her hair, her pregnant state stands against a cosmic background of death (Nešic 1998, 749). His Hope II is no different; but instead of a nude, one finds a pregnant woman dressed in a colorful, geometric cloak that wraps below her exposed breasts. She bows her head towards her swelling belly with a raised left hand. Three women kneel below her with their hands raised as if in praise or prayer while a skull hangs on her left, a possible symbol of death or labor. These visions of hope in the experience of pregnancy transform how the feminine physique and the female condition are celebrated and appreciated. Paula Modersohn-Becker's Self-Portrait on Her Sixth Wedding Anniversary (1906) was painted in anticipation of her future pregnancy. The longing and ambition to celebrate the gift of life and joys of physical transformation through pregnancy are positively portrayed in her work. Her painting features her in "a three-quarter length nude with an amber necklace; she encircles her rounded stomach with her two hands and seems to peer into a mirror"' (Nešic 1998, 750). She sees herself as an image of a proud would-be mother gazing into the future of her growing child within. Yet, with themes such as hope, pride, and happiness, they lead us to question how they coexist with women's perception of their pregnant sexual bodies as well as how the attractiveness of these bodies are perceived by others.

In The beauty of pregnancy in art from modernism till now (2018), Angie Kordic (2018) claims that pregnancy in art is a "rare sight" and some "call out the influence of the taboo behind the immaculate conception of Virgin Mary." For many women, 
pregnancy is a time when they are insistently reminded that they are bodies, and bodies in flux at that. Pregnant women are almost always faced with questions about what it means to be seen differently and what it means to see oneself differently. One aspect of this phenomenon has to do with the way pregnant women are often seen as unfit subjects of sexual interest, or at least inappropriate objects for a sexual gaze (Mullin $2005,19)$. A woman's pregnant body discloses her secret life to all, proclaiming she is sexually active and fertile. In turn, strangers may feel entitled to pass remarks or hand out unsolicited advice (Raphael-Leff 2001, 16).

Similarly, in Knock me up, knock me down: Images of pregnancy in Hollywood film and popular culture (2013), Kelly Oliver (2013, 241 - 262) discusses the images of pregnant bodies popularized by Hollywood films, media, and pop culture. Her essay tackles such issues as 1) some representations of women's pregnant bodies eroticizes/sexualizes pregnancy, 2) the pressure to maintain a slim body during pregnancy, or to immediately lose the baby weight gained after pregnancy. However, regardless of societal and patriarchal barriers that impede women's claim on their pregnant bodies, images of pregnant women continue to assert their freedom to do so. As a result, these positive images of pregnancy slowly penetrate not only the art world but popular and social media as well.

Like Becker, Alice Neel's Pregnant Maria (1964) and Pregnant woman (1971) concentrates on the feminine sexuality of a pregnant body. This feature of a sexually confident pregnant woman has been said to connote the eroticism and sensuality or "to-be-looked-at-ness" alluded by the female nude. Unlike the generic nude, however, the pregnant female nude seems to block if not reverse the gaze and claims it as her own. In their Pregnant Pictures (2000), Sandra Matthews and Laura Wexler (2000, 21) quote art historian Pamela Allera's assessment of Neel's Pregnant Maria (1964), stating that,

No fantasies of possession are possible when her very condition indicates a prior claim to this property. Because her sexual history is inscribed on her body, the male gaze cannot penetrate her. Maria presents her body to be surveyed, but with the erotic gaze blocked, her gaze and its desire dominate.

Matthews and Wexler $(2000,21)$ emphasize that "Maria's pregnant belly implies an already-spoken-for sexuality that underlines the contradiction of using a maternal figure to provide the public with the voyeuristic mastery of erotic viewing." The female empowerment that these pregnant images bring transcends the popular view that pregnant women are undesirable, bloated, and alienated. Instead, images such as Pregnant Maria (1964) aim to reclaim pregnancy as the woman's experience of her physical, sexual, and emotional transformation, and to a certain extent, her own pleasurable desires.

Thereafter, with the popularity of photographic art, artists began to endorse the beauty of pregnant pictures. Contrary to most pregnant images in the form of sculptures, wood carvings, and paintings, pregnant photographs often take on a scopic view 
(Matthews and Wexler 2000, 20). Scopic photographs take after "scopophilia," a term that implies the "pleasure in looking." This way of looking involves a sexually objectifying gaze towards the stylized nude female. Laura Mulvey further elaborates this in her Visual pleasure and narrative cinema (1973). As images of women are fashioned to hold the objectifying gaze, it is presumed that this voyeuristic and sexual theme also applies to photographic images of pregnant women (Matthews and Wexler 2000, 20). Gerard Malanga's Esther, 7 months (1985), Harry Callahan's Eleanor (1949), and Bob Saltzman's untitled photograph of two nude, pregnant women floating in a pool of water creates the voyeuristic experience while strategically reversing the mostly male, objectifying gaze.

In support of this reversal, female artists reclaim women's bodies by projecting the woman's gaze through their pregnant subjects while distancing and disregarding cultural and social scrutiny. In Barbara Morgan's Pregnant (1943), a pregnant woman is posed against a dark background with her breasts and belly highlighted in the foreground. The emphasis on her magnificent belly and full breasts illustrate a "contemporary equivalent of a fertility goddess" (Matthews and Wexler 2000, 30-33). Matthews and Wexler explain that the image would "indicate that the pregnant woman needs to be concerned only with her own ripe body and the protection it affords the pleasantly burgeoning life within." Without any sign of shame or prudence, the image exudes pride, sexuality, and the affirmation of her body as her own. In support of this prenatal confidence, Ruth Bernhard's Seed (1971) proudly signifies the sexuality of a pregnant woman. Albeit clothed in a maternity dress, she sits visually encapsulated like a Madonna."The woman's flowing clothing accentuates her enlarged breasts, her belly and the division between her legs, while at the same time it suggests her modesty"(Matthews and Wexler 2000,39). What makes this image shrouded with more symbolism and intrigue is the small seedling nestled in a rectangular pot between her hands atop her crotch. A single sprout shoots from a giant seed, which seems to suggest that like the promise of her seedling comes the promise of the little human planted inside her. Her Madonna-like demeanor is reflected by the way she carries both her belly and the seeded box. Matthews and Wexler (2000, 39-41) further posit that,

The seed and sprout carry multiple associations to both male and female genitalia. The way the woman encloses the box with her hands and presses it to her body raises the possibility of self-insemination. Thus we have an image of the complicated, multiply gendered, and simultaneously self-contained sexuality of a pregnant woman. The box is a frame within a frame, an external representation on several levels of what is going on inside the woman's draped body. The sexual content of the Bernhard photograph serves as a subtext within the overall frame of the pregnant woman as Madonna.

Unlike Morgan and Bernhard's work, Imogen Cunningham's Behind the screen (1957) captures the pregnant nude behind a dividing screen in the midst of nature while allowing the viewer a glimpse of a middle-class lifestyle. The view of the woman's nakedness is strategically intercepted by the overcast of mesh that seems to isolate her from public exposure. Amid trees and a grassy lawn, the pregnant woman challenges 
the typical domesticated image of women. "Cunningham's photograph uses the lyrical, romantic mode of picturing middle-class pregnancy, while also commenting astutely on the marginal, isolated, liminal social place of the middle-class pregnant woman" (Matthews and Wexler 2000, 33).

From challenging the objectifying gaze to endorsing one's sexuality and social class, employing pregnant subjects that challenge feminine archetypes has also paved its way through art photography. Jack Welpott's Anna (I) (1964) is an atypical representation of a pregnant woman. The image shows a pregnant subject dressed in a carnival-themed costume fit for a medieval gypsy while staring down at any would-be spectator. Her exposed belly protrudes in the foreground with both her hands bent on her sides as she stands proud, dominating, and unbothered, almost questioning the look one gives her. Welpott "represents the woman as a powerful self-parodying agent who appears to flaunt her pregnancy as an emblem of female sexuality" (Matthews and Wexler 2000, 41). The hunger to uphold and reclaim one's power and sexuality has come a long way as the means by which women challenge the prototype image of a pregnant woman have gone farther and more radical. By seeping into social media and popular culture, women are now unafraid to express and seize every opportunity to enforce their intent to transform and educate society's perception of their pregnant bodies.

George Lois '(2011) Flashback: Demi Moore recalls the magazine cover by Vanity Fair (August 1991) that struck everyone depicting "a famous movie star beautifully bursting with life and proudly flaunting her body." This photo immediately received various criticisms, quickly making it a culture buster, driving those that regarded a pregnant female body as "grotesque and obscene." The image of Demi Moore supporting herself with a hand-bra in order to cover her own body was able to convey a message that a woman, much more a pregnant one, was able to support herself in a time of struggle, or in this case, labor. This dramatic symbol of female empowerment was indeed a show of bravery for women around the world.

In an equally familiar scenario, the online article of Fashionista entitled $A$ history of naked, pregnant celebs on magazine covers (2012), Nora Crotty recounts how celebrities back then were, just like ordinary citizens, reluctant to show their baby bumps, let alone pose naked at the same time. Demi Moore sparked a trend that erupted into other celebrities posing nude for various newsstands (Crotty, 2012). Likewise, other pregnant women such as Cindy Crawford ( $W$ in June 1999), Brooke Shields (Vogue in April 2003), Heidi Klum (Vitals Woman in Fall 2005), Britney Spears (Harper's Bazaar in August 2006), and Claudia Schiffer (German Vogue in June 2010) followed suit. These instances not only proved that women have become more comfortable with their pregnant bodies but that they could own their pregnant bodies.

Annie Lebowitz's photograph of the pregnant Moore in 1991, sold in a plastic wrapper to conceal her belly, outraged the public. However, it also shifted the representation of the pregnant body (Oliver 2013,249). Before Moore, images of pregnancy and women's pregnant bodies were not displayed with great pride, nor were they given so much attention. Right now, "pregnancy has even become something of an obsession in popular culture, where paparazzi are constantly on the lookout for celebrities 'telltale 
"baby bumps" and heavily pregnant bellies" (Oliver 2013, 241). One drawback with this, though, is that women are not only expected to stay youthful, beautiful, and sexy, but they are expected to maintain that image even in pregnancy, or else to gain back that image right after their baby is born. Unfortunately, pregnant women are also objectified and gazed at. "The way that pregnancy has become a hot image for Hollywood and the tabloids continues a long tradition of objectifying and sexualizing women's bodies" (Oliver 2013, 251). However, the trend of associating pregnant bodies with sex has highlighted women not only as sex objects but as fertile subjects as well. This is a far cry from Beauvoir's $(2011,621)$ claim that pregnancy is not appealing since pregnancy supposedly deforms women's bodies.

Nowadays, representations of pregnant women in media support the idea that "women are actively seeking reproduction as a means of fulfillment to compliment career success and other achievements" (Oliver 2013, 258). Pregnancy has become not only a means to encourage women to love and reclaim their bodies and accept its capability, but it has become a way to showcase a woman's vital role in reproduction amidst all her other potentials.

While the bump showcases the uterus stretching to accommodate life, one must go beyond it and look at what it symbolizes as well---the struggles women face throughout conception, pregnancy, and childbirth. Conceiving, carrying, and giving birth to a child is a transformation. Although considerably possessed by patriarchy, beautiful, and taboo representations, the collective pregnant feminine is a significant experience that should be explored and reconceived.

\section{RECONCEIVING THE PHILOSOPHY OF PREGNANCY}

Ancient images provided the tapestry from which we ought to look back to when pregnancy was celebrated and revered through the femininity, fertility, and maternal care of the goddess. The Paleolithic and Neolithic images only remind us that the revival of these ancient images can be a way to go against male-dominated inflictions and that to revisit them is to reconceive the philosophy of pregnancy. The significance of reclaiming pregnancy through these images is founded on the idea that as andividual, a pregnant woman "constructs her sense of self in part from the images of herself, so does our society derive a sense of collectivity from the images it constructs and circulates" (Matthews and Wexler 2000, 2). At the same time, by revisiting these pregnant images, we reconsider how we look at pregnant women and how they look at and create images of themselves for themselves. So much so that the veneration of female pregnancy through the fertility goddess has been recreated and re-imagined in contemporary art and photography in an attempt to revive such power and confidence.

By invoking the feminist images that promote women's empowerment, contemporary images of pregnancy not only continued where ancient images left off but responded to the problems imposed by patriarchal standards and Christian iconography. These images summoned themes that counter the negative connotations that dominated the previous era. Concern for the right of passage, the abundance and fertility of women in her prenatal stage came hand in hand with her positive images of hope and happiness. 
Given that pregnancy arouses various emotions and behaviors towards the female body, contemporary works have forgone the depiction of the biological, economic, and psychological exhaustion of pregnancy. Instead, they focused on the woman's body as a fertile, sexual, independent, expressive, and dominant structure for sociocultural change. This change is a transition from patriarchal beliefs towards pregnancy to new ideologies that support pregnancy; one takes into account women's lived experiences of it. Her body is not simply considered as a repository of the flesh; rather, it emphasizes the fulfillment of her own desires.

Through the novel themes brought forth by contemporary images, we are able to unearth the inspiriting sexuality and desirability of pregnant women. However, "difficulties in representing pregnant women also reflect the fact that Western cultures have tried to separate the maternal from the sexual in women's roles and women's lives" (Matthews and Wexler 2000, 13). The images that represent a shift, an attempt to rewrite the former dogmas, prove that it is possible to change the previous structures. There exists a steady decision to unite women's maternal and sexual roles through these new images. The pregnant body remarkably reverses the objectifying gaze that accompanies the generic female body. In support of this reversal, female artists are able to recreate and modify the images they make to reclaim women's bodies by transmitting their gaze through their pregnant subjects. This becomes the turning point in the project of countering the ill-perceived norms towards the pregnant body. As Matthews and Wexler $(2000,16)$ state,

Shielding pregnant women's bodies from view can conceal attempts to control women's role in human reproduction as the science of pregnancy progresses...[t]he pregnant woman as an individual needs to look at representations of her state in order to better see herself, but images of pregnancy also reveal the state of society in general.

Thus, it is essential to ensure that both individual and society work towards a reflection of the same feminist image of pregnancy. Through these first-person, subjective narrations, and visual representations, the uniqueness, and temporalities of the pregnancies are embodied. The prehistoric pregnant women are represented as they are, beautiful women, not grotesque, the way masculine writing has portrayed Medusa. The examples of contemporary women proudly showing off their pregnant bellies and speaking of their own experiences through their own voices have paved the way for women's reclamation of their glorious pregnant bodies.

Through our process of reviving and examining positive images of pregnancy from the ancient to contemporary times, we were able to identify those that uphold feminist ideals. The attitude that these images have displayed pushes us to embark on the practice of supporting how women not only create images of themselves as pregnant bodies but also how these images encourage change in the way society views, recreates, distributes, perpetuates, and sustains images of pregnancy. By recognizing the images that challenge the norms brought by patriarchal systems, we are thereby rewriting--and causing a paradigm shift in--the philosophical discourse on pregnancy. 
It must acknowledge its former limitations and open itself up to a richer and more significant dialogue that involves women, not as mere problematic bloated bodies, but as agents that experience the complex process of pregnancy and childbirth.

Advocating Cixous 'strategy of rewriting and reformulating the structures of language, we have unearthed images that differentiate themselves from the pregnant archetypes, perceptions, expectations, and assumptions that surround it. Re-imagining pregnancy through these revolutionized pregnant images may eventually rewrite the language we associate with pregnancy in general. The kind of philosophical discourse one recreates would also depend on this change of language, thus modifying how we philosophize about pregnancy and the pregnant body.

In realizing the significance that sexuality, iconography, and childbirth hold on the pregnant body, we understand that reproduction, female sexuality, and childbirth are powerful aspects solely bestowed on women. And "while experiences of childbearing are diverse, pregnancy can have a significant erotic dimension for both men and women" (Matthews and Wexler 2000, 13).

\section{CONCLUSION}

Through these images, we have shown how women have indeed struggled against patriarchal systems that have positioned the female body as shameful and vulgar. Due to centuries of strife, images have also evolved by exhibiting women who ultimately decided to break free from censoring their pregnant condition. Conservatism is challenged through a revolt against images that censor the bump as well as associate pregnancy with sorrow, regret, violation, disgust, alienation, and poverty. The transition of the pregnant images has undergone a number of overhauls at varying stages of history that result in the courage of women to flaunt their bodies and claim their pregnancy not in anger but in their fearlessness to bathe in the beauty that accompanies the experience of pregnancy and childbirth.

The many ways pregnant images have been presented, the kinds of pregnant images that have existed, and the change they undergo through the years are a reflection of how the female body has been continuously recreated. It is important to note that such a change affects all aspects of our environment. Education, society, business, media, and culture all rely on how and what images we continue to form and allow (Matthews and Wexler 2000,2). The success of philosophical discourses on pregnancy is also dependent on the language and ideologies we continue to create and sustain. The more women write about pregnancy through their own beautiful experiences constructed by their own image, women would be able to dismantle that which hinders their progress and demands for change.

The bump, which is definitely more than just evidence of the uterus stretching to accommodate the fetus, is now a symbol of women's triumphs and struggles all throughout conception, pregnancy, and childbirth. We reveal that through a revival of ancient narratives and an examination of contemporary images of pregnancy, we may reconceive and repossess a new philosophy of pregnancy that challenges existing patriarchal systems. 


\section{ACKNOWLEDGMENTS}

We are grateful to Teddy John Hablado for sharing his insights on Hélène Cixous's theories; he inspired the writing of certain parts of this paper. We also thank the editors of this journal and the anonymous reviewers of our paper for their careful reading and constructive feedback. Ninotchka Albano thanks the Doctoral Apprenticeship Program of De La Salle University's Office of the Vice-Chancellor for Research and Innovation (DLSU-OVCRI).

\section{REFERENCES}

Bibby, Michael. 1996. Hearts and minds: Bodies, poetry, and resistance in the Vietnam era. New Jersey: Rutgers University Press.

Butterfield, Elizabeth. 2010. Days and nights of a new mother: Existentialism in the nursery. In Motherhood, philosophy for everyone: The birth of wisdom. Edited by Sheila Lintott. Sussex, UK: Blackwell Publishing. pp. 63-76.

Campbell, Joseph. 1976. Primitive mythology: The masks of God. New York, London, Victoria, Ontario, Auckland: Penguin Books.

Cixous, Hélène, Keith Cohen and Paula Cohen. 1976. The laugh of the Medusa. Signs. 1 (4). pp. 875-893.

Crotty, Nora. 2012. A history of naked, pregnant celebs on magazine covers. In Fashionista. Available at http://fashionista.com/2012/03/a-history-of-nakedpregnant-celebs-on-magazine-covers. Accessed: June 28, 2016.

de Beauvoir, Simone. 2011. The second sex. Trans. by C. Borde and S. MalovanyChevallier. New York: Vintage Books.

Diprose, Rosalyn. 1994. The bodies of women: Ethics, embodiment, and sexual difference. London: Routledge.

Ehrenreich, Barbara and Deirdre English. 1978. For her own good: Two centuries of the experts 'advice to women. New York: Anchor Books.

Freud, Sigmund. 1963. Medusa's head. In sexuality and the psychology of love. New York: Collier. pp. 212-213.

Frymer-Kensky, Tikva. 1993. In the wake of the goddesses: Women, culture and the biblical transformation of pagan myth. New York: Fawcett Columbine.

Gray, Frances. 2013. Original habitation: Pregnant flesh as absolute hospitality. In Coming to life: Philosophies of pregnancy, childbirth, and mothering. Edited by Sarah LaChance Adams and Caroline R. Lundquist. New York: Fordham University Press. pp. 71-87.

Guenther, Lisa. 2013. The birth of sexual difference: A feminist response to MerleauPonty. In Coming to life: Philosophies of pregnancy, childbirth, and mothering. Edited by Sarah LaChance Adams and Caroline R. Lundquist. New York: Fordham University Press. pp. 88-108.

Ions, Veronica. 1968. Egyptian mythology. London, New York, Sydney, Toronto: The Hamlyn Publishing Group, Lid. 
Keen, Sam and Anne Valley-Fox. 1989. Your mythic journey: finding meaning in your life through writing and storytelling. New York: G. P. Putnam's Sons.

Kordic, Angie. 2018. The beauty of pregnancy. In art from modernism till Now. Available at https://www.widewalls.ch/pregnancy-art/. Accessed: June 2, 2018.

Lois, George. 2011. Flashback: Demi Moore (Esquire legend George Lois recalls Annie Leibovitz's culture-jolting 1991 V.F. cover of a pregnant Demi Moore). Available at http://www.vanityfair.com/news/2011/08/demi-moore-201108. Accessed: June 23, 2016.

Matthews, Sarah and Laura Wexler. 2000. Pregnant pictures. New York: Routledge.

Mullin, Amy. 2005. Reconceiving pregnancy and childcare: Ethics, experience and reproductive labor. New York: Cambridge University Press.

Nešic, Beth Gersch. 1998. Pregnancy. In Encyclopedia of comparative iconography: Themes depicted in works of art. Edited by Hélène Roberts. Chicago, USA and London, UK: Fitzroy Dearborn Publishers. pp. 745 - 752.

Oliver, Kelly. 2013. Knock me up, knock me down: Images of pregnancy in Hollywood film and popular culture. In Coming to life: Philosophies of pregnancy, childbirth, and mothering. Edited by Sarah LaChance Adams and Caroline R. Lundquist. New York: Fordham University Press. pp. 241-262.

Raphael-Leff, Joan. 2001. Pregnancy: The inside story. New York: Karnac Books.

Stone, Merlin. 1976. When god was a woman. San Diego, New York, London: Harcourt Brace Jovanovich, Publishers.

Tyler, Imogen. 2000. Reframing pregnant embodiment in Transformations: thinking through feminism Edited by Sarah Ahmed, Jane Kilby, Celia Lury, Maureen McNeil, Maureen Mcneil and Beverley Skeggs. London: Routledge, pp. 288- 302.

Verhage, Florentien. 2013. The Vision of the Artist/Mother: The Strange Creativity of Painting and Pregnancy. In Coming to life: Philosophies of pregnancy, childbirth, and mothering. Edited by Sarah LaChance Adams and Caroline R. Lundquist. New York: Fordham University Press. pp. 300-319.

Walker, Barbara. 1983. The Woman's Encyclopedia of Myths and Secrets. New York: Harper Collins Publishers.

Walker, Barbara. 1988. The Woman's Dictionary of Symbols and Sacred Objects. New York: Harper Collins Publishers.

Weber, Sandra and Claudia Mitchell. 2004. Not Just Any Dress: Narratives of Memory, Body and Identity. New York: Peter Lang Publishing, Inc. 